\title{
Properties of Water-Repellent Fabrics
}

\author{
By John W. Rowen and Domenick Gagliardi
}

\begin{abstract}
A review and an analysis of the theory of water repellency of textile fabries have been made. The physicochemical basis underlying the wettability, or water repellency, of treated fabrics is discussed. A survey of the laboratory test methods for evaluating water repellency of textile fabrics is presented. A study was made of the water-repellent properties of 11 commercial raincoat and 4 military fabrics. For this study two of the more recent test methods were examined, the drop-penetration and the contact-angle tests. Two other, and older, test methods were also studied, the spray-rating and the hydrostaticpressure tests. Several exploratory observations were made in an attempt to determine the mechanism by which water-repellent fabrics lose their repellency when exposed to rain.
\end{abstract}

\section{Introduction}

The National Bureau of Standards has been called upon from time to time to supply information dealing with "water-repellent" fabrics. These requests have usually come from Government agencies and the public at large. In recent months there has been an intensified interest in this subject, and the Bureau decided to review the field of "water repellency" and to carry out a laboratory study in order to answer present and future questions regarding this subject.

An examination of the literature [1] ${ }^{1}$ revealed the existence of a large number of chemical compounds and commercial treatments about which extraordinary claims were made. Further investigation showed that a large number of laboratory test methods had been devised for evaluating "water repellency." Moreover, considerable confusion was encountered concerning the interpretation of the test results and the meaning of such terms as "waterproof", "water-repellent", "showerproof", and "water-resistant" fabrics. It appeared desirable, therefore, to make a survey of the field

\footnotetext{
1 Figures in brackets indicate the literature references at the end of this paper.
}

of "water repellency" and to carry out some laboratory studies on currently available materials. This report, therefore, will deal mainly with the fundamental nature of "repellency", the laboratory methods used to evaluate it in fabrics, and some laboratory observations by the authors on a variety of raincoat fabrics.

\section{Theory of "Water Repellency"}

We must at the very beginning distinguish between "waterproof" and "water-repellent" textile surfaces. There is still a great tendency to mention both terms simultaneously and interchangeably, in spite of the numerous papers $[2,3,4]$ that have been written to call attention to the great difference between them. A waterproof fabric is one in which the pores, the open spaces between the warp and filling yarns and between the fibers, are filled with appropriate substances, resulting in a fabric having a continuous surface and a very low air permeability. A water-repellent fabric is one in which the fibers are usually coated with a "hydrophobic" type of compound, and the pores are not filled in the course of the treatment. The latter types of fabrics are quite 
permeable to air and water vapor. The characteristics of the two types of fabric surfaces are summarized below :

\begin{tabular}{|c|c|c|}
\hline & Waterproof & Water repellent \\
\hline Pores & Filled.......... & Unfilled. \\
\hline $\begin{array}{l}\text { Water-vapor perme- } \\
\text { ability. }\end{array}$ & Very small_... & Small or large. \\
\hline Air permeability $\ldots$ & Small _. & Usually large. \\
\hline Chief characteristic & $\begin{array}{l}\text { Extremely resistant } \\
\text { to passage of water } \\
\text { even under a hydro- } \\
\text { static head. }\end{array}$ & $\begin{array}{l}\text { Resistant to wetting by } \\
\text { rain drops and to the } \\
\text { spreading of water over } \\
\text { the textile surface, but } \\
\text { permits the passage of } \\
\text { water under a hydro- } \\
\text { static head. }\end{array}$ \\
\hline
\end{tabular}

From the foregoing it is seen that a "waterrepellent" textile surface may never be truly waterproof and that a "waterproof" textile surface does not necessarily have to be water repellent. Unless the pores of a raincoat or shower-resistant jacket are large enough to permit transpiration, the wearer will be extremely uncomfortable due to excessive perspiration. The water-repellent fabrics are, therefore, more suited in this respect for making raincoats or shower-resistant jackets. The subject of waterproofing of textiles is very extensive and beyond the scope of this paper, therefore the discussion is restricted to the subject of water-repellent textile surfaces.

As the term implies, a water-repellent textile surface is one that appears to "repel" water. In such cases, the water does not wet or penetrate the surface of the textile fabric. The tendency of a solid to resist wetting is a function of the chemical nature of the solid surface, the roughness of the surface, the porosity of the surface, and the presence of other molecules on the surface. When a drop of water comes to rest on a solid, it may assume one of the forms shown in figure 1, or any intermediate form from complete wetting to complete nonwetting. Which form the drop will take is determined by the above-mentioned variables.

Examination of the angle of contact (fig. 1) the angle formed by the tangent to the drop at the point of contact with the surface (angle measured through the liquid)-reveals that the size of the angle is related to the repellency of the surface. When the angle of contact is small (under 90 degrees) the surface is said to be wettable [5, 6], and when the angle is large (over 90 degrees) the

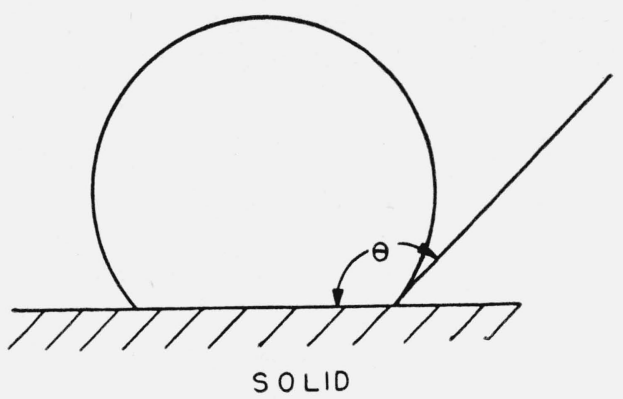

A

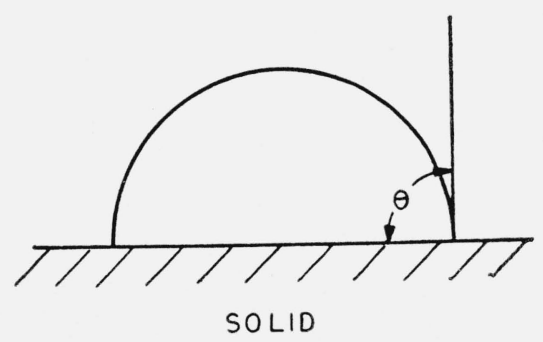

B

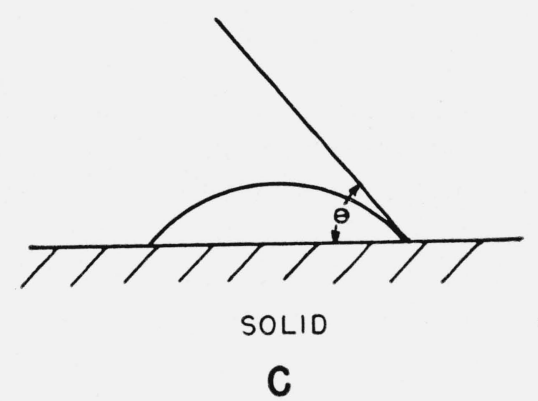

Figure 1.-Shapes of drops on solid surfaces.

$A$, Contact angle between 90 and 180 degrees; $B$, contact angle of 90 degrees; $C$, contact angle between 0 and 90 degrees.

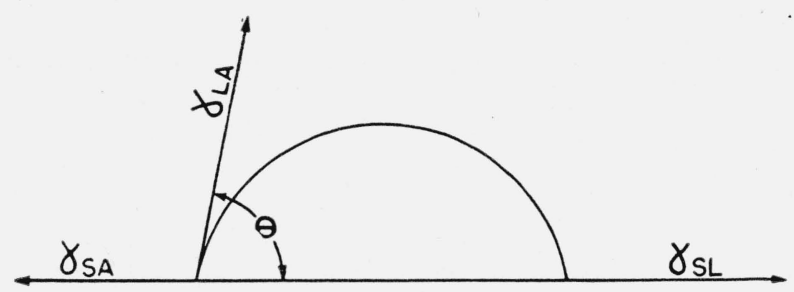

FIGURE 2.-Forces acting at equilibrium on drop-solid system.

surface is $\mathbf{T}_{\text {said }}$ to be nonwettable, or repellent. Further consideration of the energy relationship of the drop-surface system as depicted in figure 2 reveals that the equilibrium condition is due to 
the following surface energies: $\gamma_{s a}, \gamma_{l a}, \gamma_{s l}$, where $\gamma_{s a}$ is the free surface energy per square centimeter (numerically and dimensionally equivalent to the surface tension) of the solid in contact with air, $\gamma_{l a}$ is the free surface energy per square centimeter of the liquid when in contact with air, and $\gamma_{s l}$ is the free surface energy per square centimeter of the solid when in contact with the liquid. At equilibrium, the following relationship holds:

$$
\gamma_{s a}=\gamma_{l a} \cos \theta+\gamma_{s i} .
$$

Dupre [7] first derived the equation relating the free surface energies with the work of adhesion:

$$
W=\gamma_{s a}+\gamma_{l a}-\gamma_{s l} .
$$

From eq 1 and 2 it follows that

$$
W=\gamma_{l a}(1+\cos \theta) .^{2}
$$

Therefore, by measuring $\theta$ and the surface tension of the liquid, one may calculate the work of adhesion between the liquid and the surface of the solid. It is clear that the smaller the work of adhesion, the smaller will be the wettability and the greater will be the repellency. For poorly

2 The work of adhesion ( $W$ ) defined above is the amount of energy necessary to destroy $1 \mathrm{~cm}^{2}$ of liquid-solid interface and to form $1 \mathrm{~cm}^{2}$ of liquid and a $1 \mathrm{~cm}^{2}$ of solid surface in contact with air. The energy of a unit area of solid surface in air may be somew hat different from the energy of a unit area of solid surface in vacuum. The difference between these two energies will depend upon the relative humidity, the hydrophobicity of the surface, the presence of transient gaseous or solids in the air, etc. It is physically impossible to separate a solid and a liquid without leaving the solid covered with at least a part of a monolayer $[6, \mathrm{p} .62 ; 8]$; however, it is desirable to define a work for such a process, which is shown to be given by

$$
W^{\prime}=\gamma_{s o}+\gamma_{l o}-\gamma_{s l},
$$

where $\gamma_{s o}$ is the free surface energy per square centimeter of solid in vacuum, $\gamma_{l 0}$ is the free surface energy per square centimeter of liquid in equilibrium with its vapor, and $\gamma_{s i}$ has the same meaning as before. Now, for the clean solid in vacuum, the following relationship (analogous to eq 1) may be postulated:

$$
\gamma_{B D}=\gamma_{l v} \cos \theta+\gamma_{s l},
$$

where $\gamma_{s o}$ is the free surface energy per square centimeter of the solid in equilibrium with saturating va por of theliquid. It follows from eq $1^{\prime}$ and $2^{\prime}$ that

$$
W^{\prime}=\gamma_{s o}-\gamma_{B o}+\gamma_{l v}(1+\cos \theta) \cdot d
$$

If we assume $\gamma_{l_{0}}=\gamma_{l_{a}}$ (which approximation is almost within experimental error), we have

$$
W^{\prime}=\gamma_{s o}-\gamma_{s o}+W .
$$

The quantity $\gamma_{s o}-\gamma_{s o}$ may be looked upon as the free energy of immersion, at constant temperature, of a unit surface of clean solid immersed in a saturated vapor and is given by [8]

$$
\gamma_{80}-\gamma_{80}=R T \int_{0}^{P} \Gamma_{2} d \ln P,
$$

where $\Gamma_{2}$ is Gibbs' "surface density" of the vapor on the solid surface and equal to $q / M \Sigma-T / V_{2}$, where $q$ is the quantity of water vapor adsorbed per gram of absorbent, $M$ is the molecular weight of the vapor, $\Sigma$ is the area in square centimeters per gram of solid, $T$ is the thickness of the surface region, and $V_{2}$ is the molal volume of the vapor.

The right-hand member of $5^{\prime}$ can be integrated if an equation for the adsorption isotherm is known or, if not, a graphical integration of the area under the isothermal curve can be carried out. repellent, easily wettable surfaces, the drop of liquid will assume a shape similar to $C$ in figure 1 ; and for highly repellent, nonwettable surfaces, the drop will assume shape $A$.

As textile fabric surfaces are not smooth, continuous surfaces, but rather porous, screen-like surfaces, one must examine the above considerations and see how they apply to textiles. Figure 3 shows the cross section of an idealized fabric.

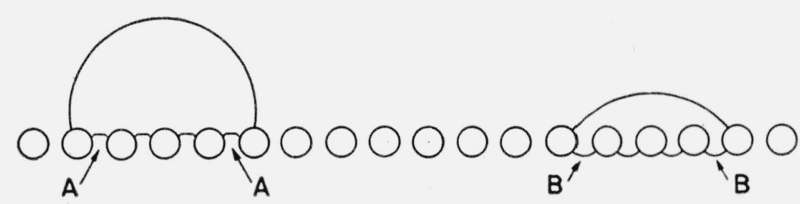

Figure 3.-Drops on surface of idealized yarn.

In this figure the parallel yarns are shown as circles. If the angle of contact between water and the surface of the fabric is larger than 90 degrees, the equilibrium position of the water level of a drop of water will be, as indicated by the line $A A$, well outside the fabric. If, however, the angle of contact is much smaller than 90 degrees, the water will penetrate the pores and the level will fall to some position such as $B B$. Cassie and Baxter [9] have shown that in the case of porous surfaces the apparent angle of contact is related to the continuous surface-water angle of contact in the following way:

where

$$
\cos \theta_{a}=f_{1} \cos \theta-f_{2},
$$

$\theta_{a}=$ apparent angle of contact

$\theta=$ angle of contact

$f_{1}=$ the fraction of the plane geometrical area of unity parallel to the rough surface occupied by the solid-liquid interface.

$f_{2}=$ the fraction of the plane geometrical area of unity parallel to the rough surface occupied by the liquid air interface.

They also derived the relationships between the " $f$ " variables, the distance between the fibers in the yarns, the radius of the fibers, and the angle of contact:

$$
\begin{gathered}
f_{1}=\frac{r}{r+d}\left(1-\frac{\theta}{180}\right) \\
f_{2}=\frac{r}{r+d} \sin \theta,
\end{gathered}
$$


where

$r=$ radius of the fibers

$d=$ one-half the distance between the fibers

$\theta=$ contact angle between the water and the fiber.

From the above, it appears as though the most water-repellent fabric will be the one on which the drop assumes a form as shown in figure 3, A. This condition may be obtained by adjusting the variables previously mentioned as being responsible for the form of the drop. It is advisable to consider each of the variables separately.

Chemical nature of the solid surface.-When purified, the natural fibers, cotton, wool, silk, etc., are hydrophilic in character and hence the drops assume shapes similar to $C$ (fig. 3). It is common practice, therefore, to treat fabrics intended to be water repellent, with various hydrophobic compounds-compositions of waxes, petroleum-like molecules, and soaps of polyvalent metals, which deposit long-chain hydrocarbon molecules on the surface of the fabric. When properly treated with a water-repellent agent, the surface of the fabric will cause a water drop to assume a form very similar to $A$ in figure 3 .

Roughness of the surface.-Wenzel [10] pointed out that roughness has a peculiar effect on the angle of contact. He employed Freundlich's [11] concept of "adhesion tension," which is defined as follows:

$$
A T=\gamma_{l a} \cos \theta .
$$

It is noted that the adhesion tension is the difference between the work of adhesion per square centimeter (eq 3) and the surface tension. Wenzel recognized that eq 7 was true only in the case where the surface was a mathematical plane. As most surfaces are not of this type, there is associated with each surface a roughness factor $R$, which is the ratio of the actual surface to the geometric surface. Wenzel showed the validity of the following equation:

$$
A T=\gamma_{l a} \frac{\cos \theta}{R} .
$$

Porosity of the surface.-Cassie and Baxter [9, 12] pursued the idea of the roughness factor and showed that the apparent adhesion tension of a porous surface was given by

$$
A T_{a}=\cos \theta_{a} \gamma_{l a}=\gamma_{l a}\left(f_{1} \cos \theta-f_{2}\right),
$$

where the symbols have the same meaning as in eq 4. Using a hexagonal idealized yarn pattern as a model, the above workers showed that $\sigma$, the bulk density of the yarn, was related to the radius of the fibers in the following way:

$$
\sigma=\left(\frac{\pi}{2 \sqrt{3}}\right) \frac{\rho r^{2}}{(r+d)^{2}}
$$

where $\rho$ is the density of the fiber. With the aid of eq $4,5,6$, and 10 , they were able to obtain plots of contact angle versus $\sigma$. These plots showed that the angle of contact approaches 180 degrees as $\sigma$ approaches small values (about 0.1 $\mathrm{g} / \mathrm{ml}$ ). Their theory led them to the position that fabric structure was extremely important in the production of water-repellent fabrics.

Presence of other molecules on the surface.- $\mathrm{It}$ is a well-known fact that the surface properties of solids may be greatly altered by covering the surface with impurities, greasy films, dust particles, water vapor and gases, etc. The presence of surface impurities may or may not be related to the fact that numerous workers [12, 13, 14, 15, 16, 17] have reported not one angle of contact with a particular system, but two angles, an advancing and receding angle. One angle is obtained when water has advanced over a surface and the other when water has receded from the surface. This difference in contact angle is often called the hysteresis of the contact angle. The cause of the hysteresis is still not clearly understood. Recently, Harkins [18, 19], working with hydrophobic materials and an improved method of measuring contact angles, found no hysteresis. Langumir [17] suggests that the hysteresis of contact angles, especially with water, is due to the presence of a surface layer of molecules with one end hydrophilic and the other hydrophobic, which are overturned by the receding water.

From the above considerations of the variables involved in water repellency, one would expect that a fabric having a high contact angle would be a water-repellent fabric. In such cases the water level will remain well outside the surface, as shown in figure $3 \mathrm{~A}$. At this point it looks as though we may be able to write a prescription for the optimum conditions for water repellency, viz, a textile fabric in which each fiber is completely coated with the material having the highest solid/ water angle of contact. It is unfortunate that this prescription has never been tested. The 
reason for this is that the present methods of treating fabrics for water repellency do not guarantee the complete coating of each individual fiber. These treatments leave many of the intertwined fibers without any surface coating. The presence of hydrophilic surfaces in the treated fabric will of course greatly diminish the over-all resistance of the fabric to wetting.

\section{Survey of Methods Used for Measuring Water Repellency in Fabrics}

The number of test methods devised for measuring water repellency appear to be almost as many as the number of laboratories engaged in this field. Comparative data from and references to the various reports on laboratory test methods have been assembled in table 1 . The object in most of these tests has been to offer a sensitive and accurate method of predicting the relative performance of fabrics in the rain. Very few, if any, of the published papers, however, have furnished any data showing the correlation between the particular test method and the performance of fabrics in the rain. Examination of the literature reveals that there is a considerable variation in the methods of testing and the interpretation of the results. It was found convenient for the

TABLE 1.-Methods and testing conditions used by various laboratories in measuring water-repellent properties of textile fabrics

\begin{tabular}{|c|c|c|c|c|c|c|}
\hline Name of test & $\begin{array}{l}\text { Refo } \\
\text { and }\end{array}$ & $\begin{array}{l}\text { rence } \\
\text { year }\end{array}$ & $\begin{array}{l}\text { Test tempera- } \\
\text { ture }\end{array}$ & Sample size & Result units & Extent of use \\
\hline \multicolumn{7}{|c|}{ CLASS $A$ TEST } \\
\hline $\begin{array}{l}\text { Hydrostatic pressure } \\
\text { Suter hydrostatic pressure } \\
\text { Mullen (high-pressure range) } \\
\text { Box test for waterproofness } \\
\text { British (DSIR) }\end{array}$ & $\begin{array}{l}{[21]} \\
{[22]} \\
{[22]} \\
{[24]} \\
{[25]}\end{array}$ & $\begin{array}{l}1941 \\
1940 \\
1944 \\
1936 \\
1925\end{array}$ & $\begin{array}{l}80^{\circ} \pm 1^{\circ} \mathrm{F} \\
80^{\circ} \pm 1^{\circ} \mathrm{F} \\
?{ }^{1}\end{array}$ & $\begin{array}{l}3^{\prime \prime} \times 3^{\prime \prime} \\
4^{\prime \prime} \times 4^{\prime \prime} \\
4^{\prime \prime} \times 4^{\prime \prime} \\
41 / 2 \times 20^{\prime \prime} \\
4.8 \mathrm{~cm}^{2} \ldots \ldots \\
\end{array}$ & $\begin{array}{l}\mathrm{cm} \\
\mathrm{cm} / \mathrm{in} .^{2} \\
\mathrm{ml} / \mathrm{min} \\
\mathrm{cm}\end{array}$ & $\begin{array}{l}\text { Wide, ASTM, and AATCC. } \\
\text { Federal Specification CCC-T-191a and } \\
\text { Supplement. } \\
\text { Do. } \\
\text { Limited. } \\
\text { Obsolete. }\end{array}$ \\
\hline \multicolumn{7}{|c|}{ CLASS $B$ TEST } \\
\hline $\begin{array}{l}\text { AATCC spray } \\
\text { Drop penetration } \\
\text { Water penetration (drip) } \\
\text { Bundesmann } \\
\text { Impact penetration } \\
\text { Spray test } \\
\text { Kern } \\
\text { Franz and Henning } \\
\text { Official German rain } \\
\text { Spray penetration }\end{array}$ & $\begin{array}{l}{[26]} \\
{[27]} \\
{[28]} \\
{[29]} \\
{[34]} \\
{[31]} \\
{[32]} \\
{[23]} \\
{[34]} \\
{[35]}\end{array}$ & $\begin{array}{l}1941 \\
1944 \\
1943 \\
1935 \\
1943 \\
1937 \\
1933 \\
1936 \\
1910 \\
1946\end{array}$ & $\begin{array}{l}80^{\circ} \pm 1^{\circ} \mathrm{F} \\
80^{\circ} \pm 1^{\circ} \mathrm{F} \\
? \\
? \\
80^{\circ} \pm 1^{\circ} \mathrm{F} \\
? \\
? \\
? \\
? \\
12^{\circ} \pm 2^{\circ} \mathrm{C}\end{array}$ & $\begin{array}{l}7^{\prime \prime} \times 7^{\prime \prime} \\
8^{\prime \prime} \times 9^{\prime \prime} \\
4^{\prime \prime} \times 4^{\prime \prime} \\
154 \mathrm{~cm}^{2} \\
6^{\prime \prime} \times 8^{\prime \prime} \\
6^{\prime \prime} \times 6^{\prime \prime} \\
4 \mathrm{~cm}{ }^{2} \\
12 \times 26 \mathrm{~cm} \\
28 \times 38 \mathrm{~cm} \\
12^{\prime \prime} \times 12^{\prime \prime}\end{array}$ & $\begin{array}{l}\mathrm{g}, \% \\
\mathrm{~min} \\
\mathrm{sec} \\
\mathrm{ml} \\
\mathrm{g} \\
\mathrm{g}, \% \\
\mathrm{No} \text { of drops } \\
\mathrm{g}, \% \\
\mathrm{~g}, \% \\
\mathrm{ml}\end{array}$ & $\begin{array}{l}\text { Very wide; AATCC; Federal Specifica- } \\
\text { tion CCC-T-191a and Supplement. } \\
\text { Federal Specification CCC-T-191a and } \\
\text { Supplement. } \\
\text { ASTM. } \\
\text { British Specifications; Germany. } \\
\text { Limited. } \\
\quad \text { Do. } \\
\text { Germany. } \\
\text { Do. } \\
\text { U. S. Navy. }\end{array}$ \\
\hline \multicolumn{7}{|c|}{ CLASS $C$ TEST } \\
\hline $\begin{array}{l}\text { Immersion } \\
\text { ASTM water-absorption (spray) method } \\
\text { Dynamic absorption } \\
\text { Bundesmann } \\
\text { Becker submersion method } \\
\text { Esslinger submersion method }\end{array}$ & $\begin{array}{l}{[36]} \\
{[37]} \\
{[38]} \\
{[39]} \\
{[40]} \\
{[41]}\end{array}$ & $\begin{array}{l}1941 \\
1943 \\
1944 \\
1935 \\
1935 \\
1940\end{array}$ & $\begin{array}{l}80^{\circ} \pm 1^{\circ} \mathrm{F} \\
80^{\circ} \pm 1^{\circ} \mathrm{F} \\
? \\
\text { Room temp } \\
?\end{array}$ & $\begin{array}{l}3^{\prime \prime} \times 3^{\prime \prime} \\
8^{\prime \prime} \times 8^{\prime \prime} \\
8^{\prime \prime} \times 8^{\prime \prime} \\
154 \ldots \ldots \\
5 \times 75 \mathrm{~cm}^{2} \\
15 \times 5 \mathrm{~cm}\end{array}$ & $\begin{array}{l}\mathrm{g}, \% \ldots \ldots \\
\mathrm{g}, \% \ldots \\
\mathrm{g}, \% \\
\mathrm{~g}, \% \\
\mathrm{~g}, \% \\
\mathrm{~g}, \%\end{array}$ & $\begin{array}{l}\text { Wide; AATCC. } \\
\text { Federal Specification CCC-T-191a and } \\
\text { Supplement. } \\
\text { Do. } \\
\text { British Specifications; Germany. } \\
\text { Germany. } \\
\quad \text { Do. }\end{array}$ \\
\hline \multicolumn{7}{|c|}{ CLASS $D$ TEST } \\
\hline $\begin{array}{l}\text { Contact angle by tensiometer } \\
\text { Wetting test } \\
\text { Wenzel method }\end{array}$ & $\begin{array}{l}{[42]} \\
{[43]} \\
{[44]}\end{array}$ & $\begin{array}{l}1945 \\
1945 \\
1936\end{array}$ & $\begin{array}{l}35^{\circ} \mathrm{C}+\ldots+\cdots \\
? \\
?\end{array}$ & $\begin{array}{l}0.196 \text { in. }{ }^{2} \\
\text { Single yarn } \\
1^{\prime \prime} \times 3^{\prime \prime}\end{array}$ & $\begin{array}{l}\operatorname{deg} \ldots \ldots \\
\sec \\
\operatorname{deg}\end{array}$ & $\begin{array}{l}\text { Experimental. } \\
\text { Do. } \\
\text { Do. }\end{array}$ \\
\hline
\end{tabular}

${ }^{1}$ Interrogation mark signifies temperature not indicated. 
purpose of this report to arrange the different test methods in four general classes:

Class $A$. Methods by which the hydrostatic pressure required to force water through a fabric is measured.

Class $B$. Methods by which surface wetting and penetration under the influence of falling drops is measured.

Class $C$. Methods by which the absorption of water by the fabric, when immersed or manipulated under water, is measured.

Class $D$. Methods by which the wettability of the surface of the fabric is measured by means of the angle of contact or some function of the angle of contact.

Some timely comments about the more popular test methods in each group are given below.

Class A.-In this class of test methods, the fabric is subjected to the action of water under pressure by a variety of means. Either the amount of water penetrating in a specified time or the pressure required to force water through the fabric is measured. The most widely used test methods in this class are the AATCC [21] and the Suter [22] hydrostatic-pressure tests. Both methods give reproducible test values. It has been reported [45] that a correlation exists between the two methods. The following relationship is supposed to hold at $27^{\circ} \pm 3^{\circ} \mathrm{C}$ :

$$
A=1.32 S-4,
$$

where $A$ is the AATCC test value, $S$ is the Suter test value.

The hydrostatic-pressure test values are dependent mainly on the pore size and the angle of contact. The bulge that occurs when the pressure is applied on the fabric requires a correction [46], but in view of the reproducibility of the test and the smallness of the correction factor, the extra measurements and calculations are usually avoided.

Class B.-The tests in this class are in some cases very different from each other. They are all, moreover, quite different from those in class $A$. All the tests in this class subject the test fabric to the action of water drops. The number, size, frequency, and energy of the drops in the various tests vary considerably. The ad- vantages and disadvantages of these various tests are briefly discussed below:

1. AATCC Spray Test. This test is very widely used in the textile industry for control work. The test will distinguish qualitatively between treated and untreated fabrics. It is not able, however, to distinguish between obviously different waterrepellent finishes or to predict the performance of a fabric in the rain.

2. Drop-Penetration Test.--This test was developed for and used by the United States Quartermaster Corps during the war. The energy of the drops used in this apparatus is approximately 10,000 to 15,000 ergs. This value is much larger than that of the drops in a cloudburst $(3,000 \mathrm{ergs})$. It appears that by this test one may be able to arrange fabrics in what seems to be a proper order of protection in the rain. The hardness of the fabric backing has a profound influence on the test value. This is probably also true for the other tests in this group. It should be mentioned that the values obtained in the drop penetration test may differ as much as 20 percent among each other, depending on the particular fabric and its test value.

3. Bundesmann Test.-The Bundesmann test was developed in Germany. It can be used in two ways: (1) to measure the amount of water penetrating the sample, or (2) to measure the amount of water absorbed by the sample in a given time. Again the drops of water in the test have energy of from 15,000 to 30,000 ergs, which is a much larger value than is found in a cloudburst. In this procedure the sample of cloth is in constant motion and is continuously rubbed on the under side during the test. When the amount of water absorbed is measured, the mean deviation [33] of the test value is reported to be about 3 percent. The method seems to offer some advantages over the other tests in class $B$ and has been recently adopted by the British Sub-Committee of the General Technical Committee as a standard test method.

4. Impact Penetration Test.-This test involves the spraying of $500 \mathrm{ml}$ of water on the test specimen. At the end of the spray period, a blotter beneath the fabric is weighed. The increase in weight of the blotter represents the amount of water that passed through the cloth. No data are available on correlation with natural rain. 
5. Spray Test.-No temperature control is specified in this test. It appears to be similar to the impact penetration test. No data are available for correlating the results of the test with results obtained with fabrics in natural rain.

6. Kern Test.-This novel method has been patented. It employs a single drop of water of definite size. An electric circuit is used to detect the penetration of the water to the under side of the test specimen. The average deviation of the test value from the mean appears to be smaller for smaller size drops. Although there appears to be a tremendous variation in the results, depending upon the fabric, the author states that seven tests are sufficient for obtaining "exact results."

Class C.-All methods in this group measure the resistance that the finish offers to wetting by water. As droplet penetration is not used in these methods, the part played by the structure of the fabric is less important than in other tests in determining the test value. The water absorbed by the fabric is measured by weighing the test specimen after some form of partial drying. In some of the tests (dynamic absorption, Becker, etc.), the sample is in motion during the test period of exposure to the water. In almost all cases the deviation of any particular test value from the mean appears to become smaller as the exposure time gets larger. The dynamic types of tests are definitely to be preferred to the static types in this category. Again, it should be pointed out that little, if any, work has been done to correlate these test results with the performance of fabrics in the rain.

Class D.-Workers who have used the following three technics have done so in an attempt to understand the mechanism of wetting. Various methods for measuring contact angles [47] have been described. The three methods which have been applied to fabrics are discussed below.

1. Wenzel Method.-Wenzel appears to have been the first to attempt to apply methods of measuring contact angles to fabrics [10]. He modified the tilting-plate method [47] to make it applicable to fabrics. Wenzel measured the contact angle of many materials, waxes, cellulose acetate, many metal stearates, rosin, and others. His data indicated that the method was applicab'e to textile surfaces and was very reproducible. At the Bureau it was found possible to reproduce the values that Wenzel obtained on paraffin wax on glass. It was found, however, that this method lacked control over the following variables: (a) Temperature, (b) rate of flow of the water over the solid surface, (c) rate of rotation of the plate in the water, and (d) cleanliness of the surface of the liquid.

2. Wetting Test.-This test measures the time for the contact angle on a yarn or strip of fabric to decrease to 90 degrees. This time has been called the "wetting time." Cassie and Baxter claim that the wetting test is more sensitive to proofing efficiency than either the Bundesmann or the hydrostatic-pressure tests.

3. Contact Angle by the Tensiometer Method.-Wakeham and Skau [42] found that, by modifying an ordinary interfacial tensiometer and forcing a circular piece of fabric through the surface of the water, they obtained a relationship between the pressure necessary to force the disk of cloth through the surface of the water and the angle of contact of the water to fabric. The method does not appear to be capable of measuring angles greater than 120 degrees. Unfortunately, the upper portion of the measurable range is the most useful from the point of view of water repellency.

The great dependence of all test values on the temperature of the water has been mentioned in several reports $[43,45,33,48]$. It is quite surprising, therefore, that many of the methods listed in table 1 appeared to be uncontrolled in temperature.

The above review of the methods used to measure water repellency indicates that no one method completely measures the phenomenon. It appears necessary that a combination of tests be used to evaluate the water repellency of a fabric. It appears possible, also, to select one test from each class and report the results in the same units. For example, the hydrostatic pressure is increased at the rate of $1.0 \mathrm{~cm}$ a second in the AATCC test. The test value could be expressed in time units. This could also be done with the drop penetration, the dynamic absorption, the wetting and other tests. One could then obtain a summary test value which would be the results of $n$ number of test values, all expressed in time units:

$$
T=f(a, b, c, \ldots . . n) .
$$

It seems reasonable to assume that the value de- 
rived from $n$ number of tests would be a more reliable measure of the repellency of a fabric than taking the value of only one test. It would remain to be proved, however, whether such a summary value gives an accurate and reliable indication of the performance of a fabric in the rain.

Considerable information obtained during the war indicates that many of the test methods given in table 1 are not applicable for evaluating the repellency of woolen fabrics [49]. All the test methods mentioned require further investigation to see whether they can be adapted for testing all types of water-repellent fabrics. It is also necessary that some of these methods be studied for the purpose of setting up commercial and Government standard methods of testing.

\section{Evaluation of Water Repellency by Typical Test Methods}

In planning the laboratory work, it was necessary to take into account the questions that are asked by Government agencies, industry, and the public at large. The following general questions are frequently asked:

To what degree is a particular fabric water repellent?
To what extent does dry cleaning and/or laundering diminish the water repellency of a fabric?

What causes a fabric to lose its repellency during the course of exposure to the rain?

In order to have available a background of information and data about water-repellent fabrics and common test methods, 11 typical commercial raincoat fabrics and 4 Army fabrics were selected for study. The characteristics of these 15 waterrepellent fabrics are given in table 2 . The waterrepellent properties were examined by the following test methods: AATCC hydrostatic-pressure test, AATCC spray test, drop-penetration test, and angle of contact test (tensiometer type).

Figure 4 shows the results obtained by the four test methods. Each test was done according to the directions prescribed in Government specifications or published papers. It is noted that the most widely used test method, the spray-rating test, did not show any differences among 12 of the 15 fabrics. Great differences among the various fabrics are revealed by the remaining three tests. As each test measures different properties of the fabrics (see section on survey of methods, p. 107), it is not surprising that the 3 tests do not rank the

TABLE 2.- Properties of 15 water-repellent fabrics

\begin{tabular}{|c|c|c|c|c|c|c|c|}
\hline \multirow{2}{*}{ Sample No. } & \multirow{2}{*}{ Type of weave } & \multicolumn{2}{|c|}{ Number of plies } & \multicolumn{2}{|c|}{ Thread count } & \multirow{2}{*}{$\begin{array}{c}\text { Air permeabil- } \\
\text { ity at a pres- } \\
\text { sure of } 0.5 \mathrm{in} \text {. } \\
\text { of water across } \\
\text { fabric }\end{array}$} & \multirow{2}{*}{ Weight } \\
\hline & & Warp & Filling & Warp & Filling & & \\
\hline \multicolumn{8}{|c|}{ WATER-REPELLENT COMMERCIAL FABRICS. } \\
\hline & Twill-tackle_... & 1 & 3 & 125 & 65 & $\begin{array}{c}\left(f t^{3} / \min \right) / f t^{2} \\
20.4\end{array}$ & $\begin{array}{c}O z / y d^{2} \\
8.6\end{array}$ \\
\hline $2 \ldots$ & do & 1 & 3 & 125 & 67 & 17.9 & 8.9 \\
\hline $3 \ldots$ & Plain-poplin ... & 2 & 1 & 107 & 51 & 5.0 & 5.8 \\
\hline $4 \ldots$ & $\ldots$ do $\ldots \ldots \ldots$ & 2 & 1 & 109 & 52 & 6.2 & 5.9 \\
\hline $5 \ldots$ & Twill ..... & 2 & 2 & 135 & 58 & 6.4 & 6.4 \\
\hline $6 \ldots$ & Plain-poplin & 2 & 1 & 107 & 55 & 8.0 & 5.7 \\
\hline $7 \ldots$ & do do _._. & 2 & 1 & 107 & 54 & 5.0 & 6.0 \\
\hline $8 \ldots$ & Twill-gabardine & 2 & 1 & 127 & 54 & 16. 2 & 6.5 \\
\hline $9 \ldots$ & Plain-poplin ...... & 2 & 1 & 106 & 54 & 4.6 & 6.3 \\
\hline $10 \ldots$ & Twill _......... & 1 & 1 & 104 & 60 & 23.6 & 7.3 \\
\hline & Plain-poplin _............ & 2 & 1 & 107 & 56 & 5.3 & 6.2 \\
\hline \multicolumn{8}{|c|}{ ARMY WATER-REPELLENT FABRICS } \\
\hline $12 \ldots$ & Sateen ........ & 2 & 2 & 115 & 70 & 3.9 & 9.1 \\
\hline $15 \ldots \ldots$ & Oxford & 1 & 1 & 134 & 53 & 3.2 & 6.2 \\
\hline $24 \ldots$ & Sateen & 2 & 2 & 115 & 67 & 3.8 & 8.9 \\
\hline $26 \ldots$ & Poplin & 1 & 1 & 53 & 52 & 4.1 & 6.2 \\
\hline
\end{tabular}


15 fabrics in exactly the same order. It is noted, however, that all fabrics can be approximately fitted into 3 general groups: good, fair, and poor.
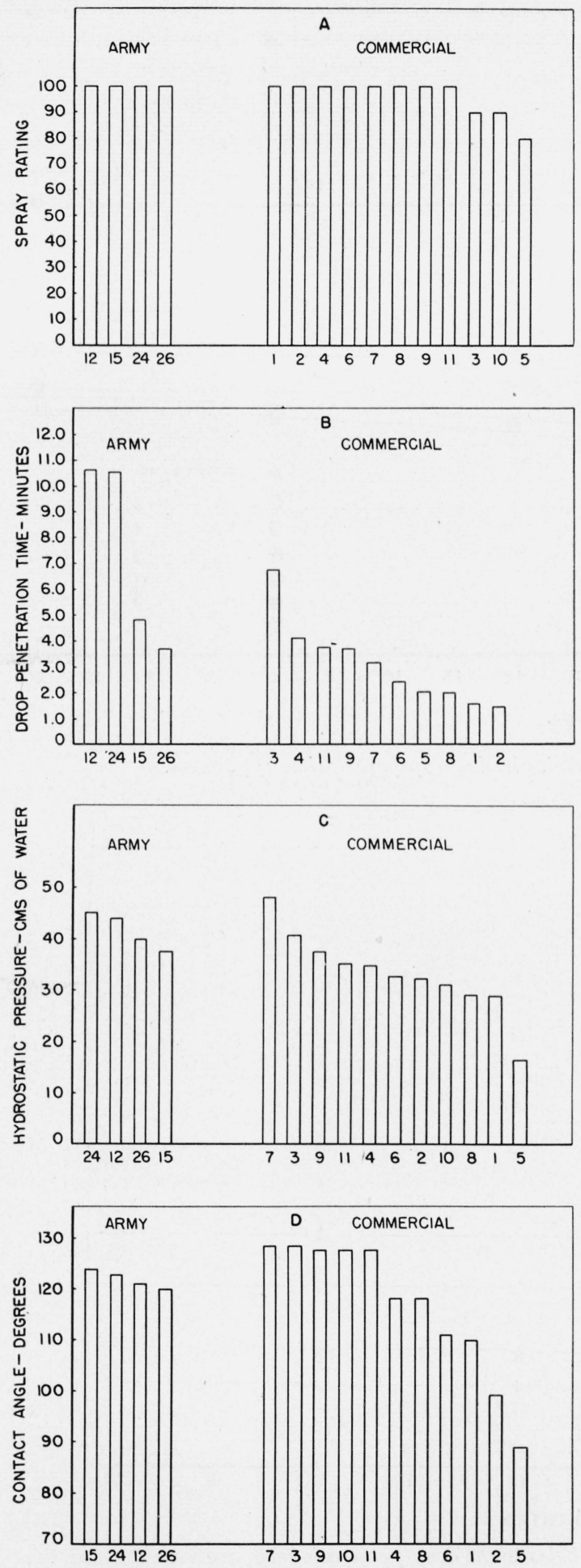

Figure 4.-Comparison of four water-repellency tests.
Certain samples always appear in a specific group: e. g. No. 5, poor; No. 3, good; No. 6, fair, etc. The fallacy of using only one test method to evaluate water repellency can be clearly seen from the data presented. It would be quite impossible to classify a particular water-repellent fabric on the basis of only one test.

Both the hydrostatic-pressure test and the measurements on contact angles reveal certain differences among the various samples not revealed by the spray test. The drop-penetration test, however, appears to be able to show differences in the fabrics that were not revealed by any of the other tests. The limitations of a particular laboratory test for evaluating water repellence are generally recognized. The most frequent argument against a certain test is that it does not test the fabric under conditions of actual use. Tests that simulate natural rain, therefore, are considered much more useful for practical testing. The drop-penetration test appears to be very useful in predicting the relative performance of fabrics in the rain. It seemed desirable, therefore, to study the present group of fabrics in greater detail on the basis of this test. In view of the arbitrariness of the test value - the time to collect $10 \mathrm{ml}$ of water passing through the test specimen - it was decided to study the rate of penetration of water through water-repellent fabrics for long periods of exposure. It was found that the "rate of penetration $(\mathrm{ml} / \mathrm{min})$ versus time curve" was very characteristic of the nature of the particular fabric. Figures 5 and 6 show plots of the rate of penetration of water against time of exposure, for 11 of the fabrics studied. The arrows in figures 5 and 6 indicate the time at which $10 \mathrm{ml}$ of water had passed through the fabric. Each rate curve contains the characteristic portions: an induction period, an S-shaped portion of a curve, and a limiting rate region. It is believed that the penetration of water through a fabric in natural rain follows a similar pattern and that the curves obtained for the drop-penetration apparatus are not a characteristic of the apparatus alone. These curves reveal that during the induction period little or no water comes through the cloth. When the resistance to penetration is finally broken, water passes through the fabric at a very rapid rate (S-shaped region). Finally, the amount of water that penetrates the fabric per unit time reaches a steady state. As 


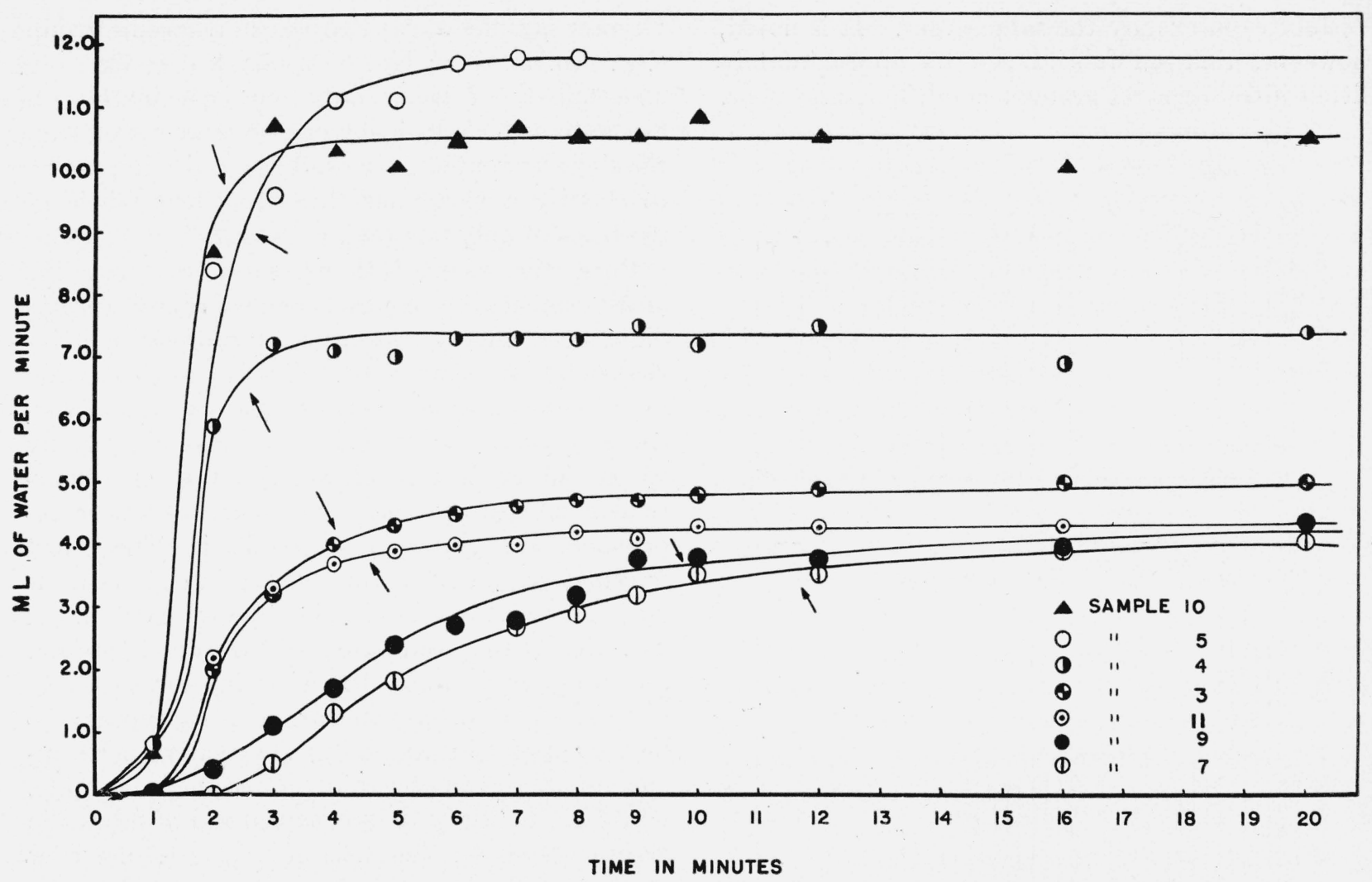

FIGURE 5.- Rates of penetration of water through fabrics in the drop-penetration apparatus. Arrows show the point at which $10 \mathrm{ml}$ of water--test value- have passed through the fabric.

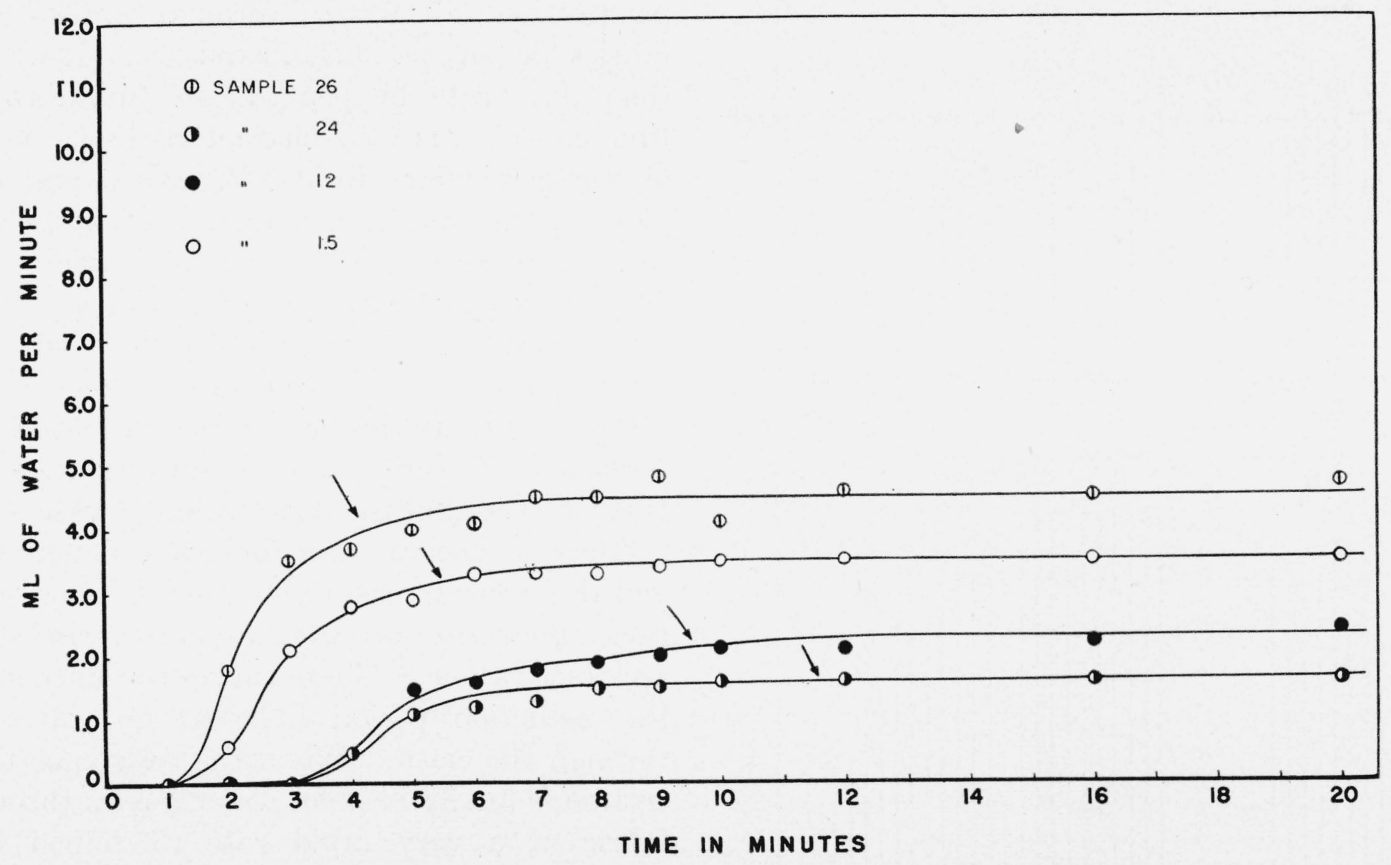

FIGURE 6.- Rates of penetration of water through fabrics in the drop-penetration apparatus. 
most of the water-repellent fabrics tested are at best only somewhat resistant to penetration, it is clear that, after prolonged exposure of a waterrepellent garment to the rain, the wearer would not keep dry. The curves also indicate that the longer the induction period, the lower will be the equilibrium rate of penetration of water. In designing new water-repellent fabrics, therefore, the object would be to fix the various variables involved so that the resulting product would have a long induction period and a low rate of penetration. Such a fabric has been designed. The Shirley type of cloths that the Army Quartermaster Corps developed during the war have a very long induction period (several hours) and a very low equilibrium rate of penetration (approximately $0.1 \mathrm{ml} / \mathrm{min}$ ). These types of fabrics are highly effective for prolonged use in the rain.

The above studies of water repellency lead to the conclusion that obtaining the rate of penetration of water with the drop-penetration apparatus gives a more complete picture of the repellency of a fabric than the $10-\mathrm{ml}$ test value by itself. This is especially significant when one is considering commercial fabrics (compare fig. 5 with 6 ). It is also concluded that better evaluation of water repellency may be made when a group of tests is employed. A study of the four test methods given above reveals that, as the rank correlation among various tests is very low, it is necessary to correlate all tests with the behavior of fabrics in natural or artificial rain. The Philadelphia Quartermaster Depot has developed and constructed
[50] a rain room for fabric and garment testing. By means of specially designed nozzles, it is possible to obtain rainfalls at the rate of $0.1,1.0$, and 3.0 inches an hour, having natural and reproducible drop-size distributions.

\section{Durability of Water-Repellent Finishes}

The durability of water-repellent finishes is generally taken to be the resistance that the finish shows to the action of dry cleaning or laundering. Durable water-repellent fabrics are those whose water repellency is only slightly diminished by dry cleaning or laundering. Those fabrics whose water repellency is totally or greatly impaired by dry cleaning or laundering are classified as being nondurable. It should be remembered that the two terms are only relative and that the difference between them is a matter of degree of resistance and not necessarily of type of compound.

The effect of dry cleaning and laundering on water repellency was studied, using only the 11 commercial raincoat fabrics given in table 2 . Standard methods of dry cleaning and laundering were used [51]. The results of these studies are given in table 3 . By the use of three different test methods, it was found possible to distinguish between durable and nondurable repellent finishes. Samples 4, 7, 9, and 11 show a smaller decrease in all test values than do the remaining samples which reveal fairly large changes in all test values. It was found that samples whose water repellency had been totally lost by dry cleaning or laundering,

TABLE 3.-Effect of dry cleaning and laundering on the water repellency of 11 commercial fabrics

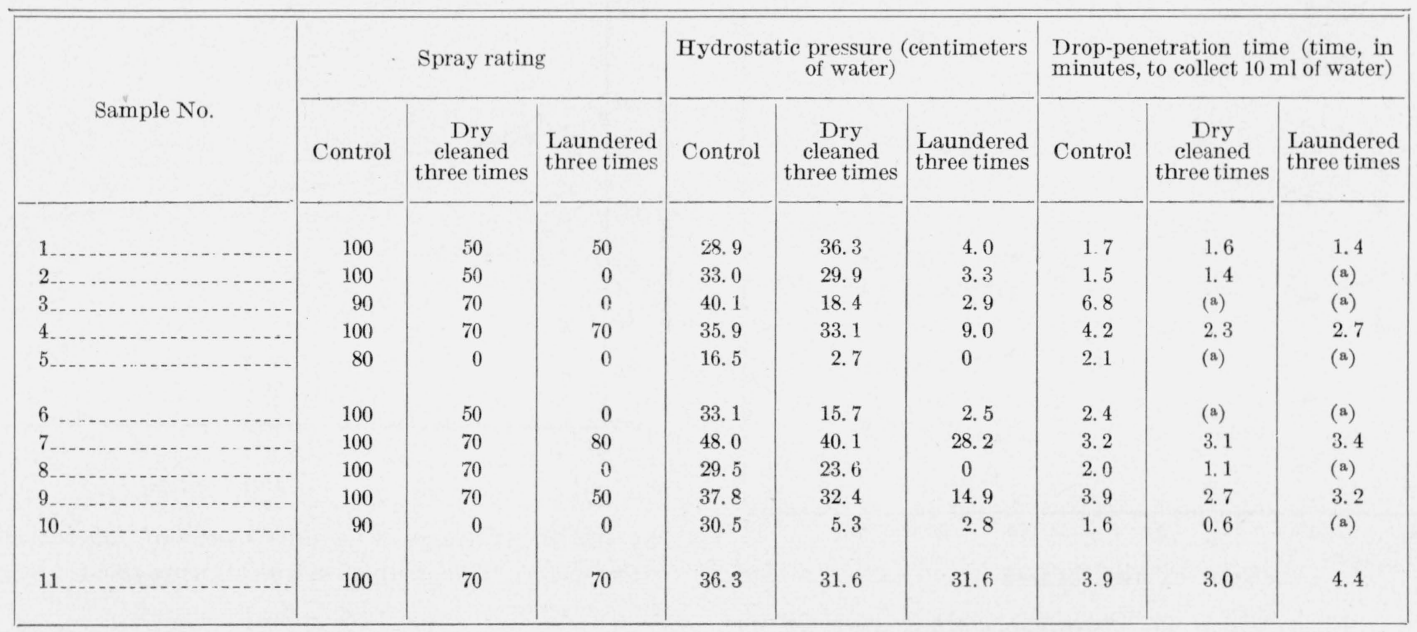

a Drop-penetration time could not be measured as the swatches became completely saturated with water at the start of the test. 
gave no test value in the drop-penetration test. These samples became completely saturated with water as soon as they were placed in the test apparatus.

The lowering of the water repellency of fabrics by dry cleaning or laundering is commonly attributed to leaching of the repellent compound. The presence of residual soap on the fabric and distortions of the fabric structure are also considered responsible for the loss in repellency. It has been observed, however, that simple wetting by water will also decrease the repellency of a fabric. Tests done at the Philadelphia Quartermaster Depot [52] have shown that water-repellent jackets were more easily wetted if they had been previously exposed to the rain. It was found that drying the jackets after the test exposure, even by heating in an oven, failed to restore to the garments their original water repellency. In view of the interest in the durability of water repellency, it seemed advisable to attempt to establish the rate at which some fabrics lose their repellency when exposed to the rain. For this study, four swatches each of five different water-repellent fabrics were tested five different days in the droppenetration test. At the end of each test period, the swatches were allowed to dry at room temperature and then were conditioned overnight at

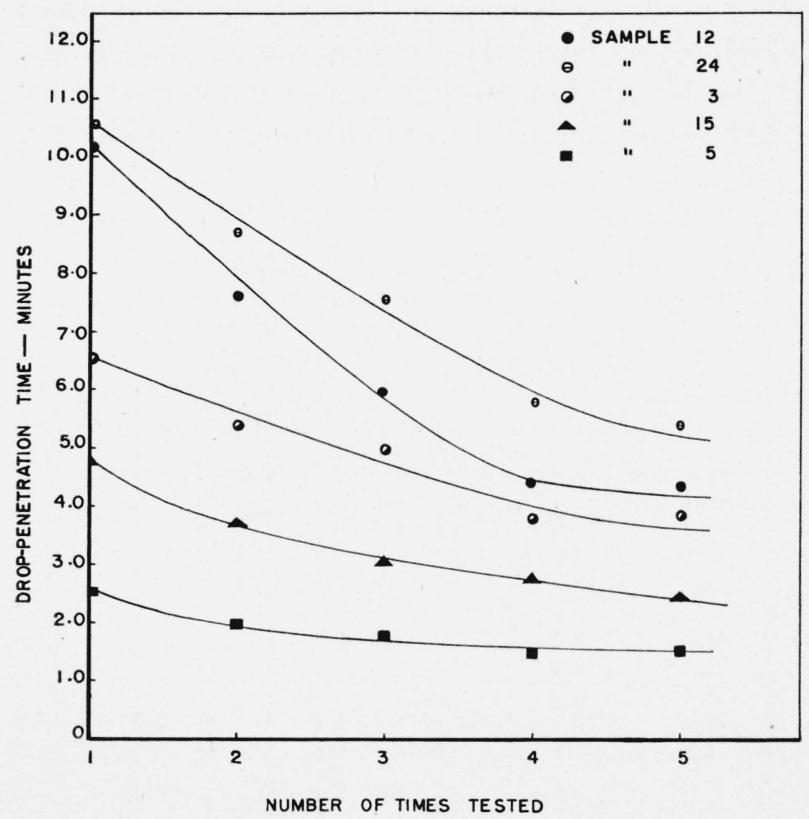

Figure 7.-Lowering of the drop-penetration time owing to repeated testing.
65 -percent relative humidity and $70^{\circ} \mathrm{F}$. The results of this experiment are shown in figure 7 . It was found that the various fabrics lose their repellency at different rates. The drop-penetration test values get progressively lower each time the swatches are tested. This loss in repellency appears to be an irreversible process. Attempts to restore the original repellency by heating in vacuum at elevated temperatures were unsuccessful. An analysis of the factors that could be causing the loss in repellency leads to the following: Loss in the repellent agent by leaching, creation of new uncoated surfaces due to swelling of fibers, and changes in the surface geometry of the fabric due to the pounding of the high energy drops. Any or all of these changes could be taking place, and they all would be irreversible changes.

In order to throw light on the loss in repellency, two simple exploratory experiments were made. The changes in the contact angle of two of the fabrics were measured after various periods of wetting in the drop-penetration apparatus. Also, the change in contact angle and the increase in "standard moisture regain" ${ }^{3}$ of one sample were noted after prolonged periods of spraying. The spraying was done with the nozzle of the AATCC spray test and was continuous for the particular period of time. The results of these observations are shown in figures 8 and 9 . The contact angle of the dry fabrics was found to be lower after

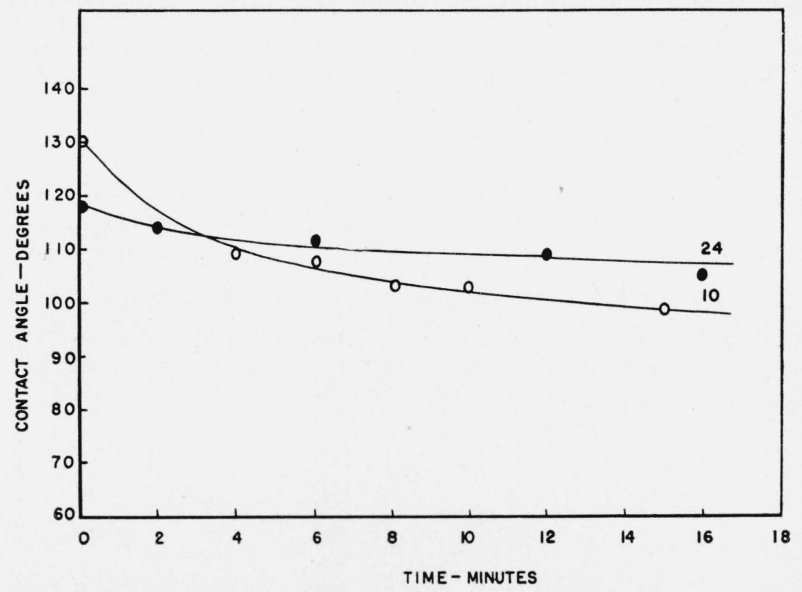

Figure 8.- Change in contact angle of fabrics exposed in the drop-penetration apparatus.

${ }^{3}$ Regain in weight during a 24-hour exposure period to 65-percent relative humidity and $70^{\circ} \mathrm{F}$. 
each period of wetting in the drop-penetration test. The contact angle of one of the fabrics was also lowered after spraying the sample for various times. Swatches of this fabric, when sprayed and then tested for standard moisture regain, showed an increase in rate of moisture absorption. It is emphasized that the increase is an increase in rate (per 24-hour period) as the "repellent" fabrics do not always reach equilibrium in this length of time.

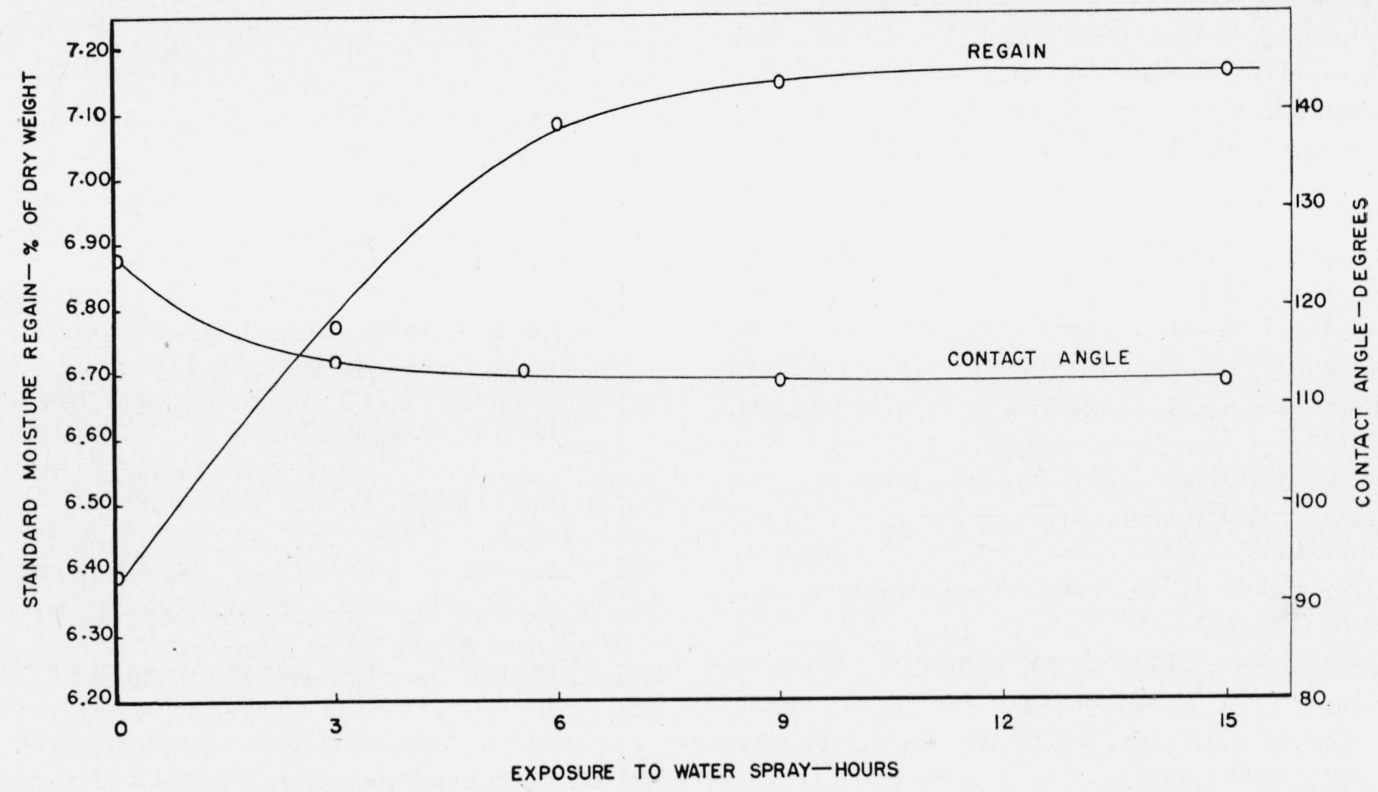

FIGURE 9.-Changes in the contact angle and the standard moisture regain of a 9-ounce waier-repellent fabric after prolonged spraying with water.

\section{Summary and Conclusions}

The theory of water repellency of textile fabrics has been reviewed with special references to the more recent theories of the wetting of fabrics by water. A survey has also been made on the various testing methods that have been devised for measuring water repellency. The results of the present investigation lead to the following conclusions regarding the status of water repellency. There is definite need for a comprehensive study of the role that the structure of a fabric plays in the phenomena of water repellency. In the past, the emphasis has been on developing more efficient compounds. Data available indicate that a better understanding of fabric construction as it applies to repellency, coupled with the now available water-repellent agents, will lead to some more nearly idealized type of water-repellent garment. In regard to testing methods, it is required that correlation be established between the results of laboratory test methods and performance of fabrics in the rain.

As already stated, the contact angle is influenced by the following factors: The' chemical nature of the solid surface, the porosity of the surface, and the presence of other molecules on the surface. Again, any one or all of these factors could diminish the contact angle during wetting of the fabric. The change in moisture regain of sample 24 (fig. 9) shows that the rate at which a fabric absorbs moisture increases in proportion to the number of times the sample has been wetted. It is of interest to examine the surface factors that might be responsible for the increase in moisture absorption. The loss in repellent agent, the change in position of the fibers in the yarns, and the creation of new surfaces could all affect the rate of water absorption. The swelling of partially coated or uncoated fibers would also result in making available more hydrophilic surfaces (OH groups) [53]. 


\section{References}

[1] Chemical Abstracts for 1942 and 1943, for example.

[2] H. P. Pearson, Waterproofing textile fabrics (The Chemical Catalog Co., Inc., New York, N. Y., 1924).

[3] D. A. Martin, Am. Dyestuff Reptr. 21, 126 (1932).

[4],G. A. Slowinske, Am. Dyestuff Reptr. 32, 85 (1943).

$[5]_{4}^{*}$ F. E. Bartell and F. J. Osterhof, J. Phys. Chem. 34, 1399 to 1411 (1930).

[6] J. Alexander, Colloid chemistry 6, 313 (Reinhold Publishing Corporation, New York, N. Y., 1946).

[7] Dupré, Théorie Méchanique de la Chaleur, 369 (1869).

[8] J. Alexander, Colloid chemistry 6, 62 (Reinhold Publishing Corporation, New York, N. Y. 1946); G. E. Boyd, Surface chemistry, p. 133 (Am. Assn. Adv. Sci. No. 21, 1943).

[9] S. Baxter and A. B. D. Cassie, J. Textile Inst. 36, 167 (1945).

[10] R. Wenzel, Ind. Eng. Chem. 28, 988 (1936).

[11] A. Harvey, Wetting and detergency, p. 18. (The Chemical Catalog Co., New York, N. Y., 1937).

[12] S. Baxter and A. B. D. Cassie, Trans. Faraday Soc. 40, 546 (1944).

[13] L. Rayleigh, Phil. Mag. [5], 30, (1890).

[14] A. Pockels, Phys. Z. 15, 39 (1914).

[15] F. E. Bartell and Cardwell, J. Am. Chem. Soc. 64, $164,494,1530$ (1942).

[16] J. Ablett, Phil. Mag. [6] 46, 244 (1923),

[17] N. K. Adam, The physics and chemistry of surfaces, p. 181, 2d ed. (Clarendon Press, Oxford, England, 1938).

[18] W. D. Harkins, J. Am. Chem. Soc. 62, 3381 (1940).

[19] J. Alexander, Colloid chemistry 6, 61 (Reinhold Publishing Corporation, New York, N. Y., 1946).

[20] F. L. Gleysteen and V. R. Dietz, J. Research NBS 35, 285 (1945) RP1674.

[21] Am. Assn. Textile Chem. Colorists, 1944 Year Book, p. 206.

[22] Am. Assn. Textile Chem. Colorists, 1940 Year Book, p. 223.

[23] U. S. Army Spec. 100-48, p. 20 (May 11, 1945).

[24] Am. Assn. Textile Chem. Colorists, 1937 Year Book, p. 190.

[25] First report of the fabrics coordinating research committee, His Majesty's stationery office, p. 20 (London 1925).

[26] Am. Assn. Textile Chem. Colorists, 1944 Year Book, p. 210.

[27] Federal Spec. CCC-T-191a and its supplement (Oct. 8, 1945).

[28] Standards on textile materials, Am. Soc. Testing Materials, p. 82 (1943)

[29] H. Bundesmann, Melliand Textilber. 16, 128 (1935)

[30] G. A. Slowinske, Am. Dyestuff Reptr. (Feb. 15, 1943).

[31] A. A. Cook and S. Zaparavik, Am. Dyestuff Reptr. 26, 323 (1937).

[32] U. S. Patent 2,012,762.
[33] A. Klingelhöfer, H. Mendrzyk, and H. Sommer, Wiss. Abhandl. deut, Materialprüfungsanstalt. 30; Chem. Zentr. 11, 2249-50 (1940).

[34] A. Klingelhöfer, H. Mendrzyk, and H. Sommer, Wiss. Abhandl. deut. Materialprüfungsanstalt. 23; Chem. Zentr. 11, 2249-50 (1940).

[35] Harry B. Kime, Am. Dyestuff Reptr. 35, 261 (1946).

[36] Am. Assn. Textile Chem. Colorists, 1944 Year Book, op. 212.

[37] Standards on textile materials, 83, (1943).

[38] U. S. Army Spec. 100-48, p. 14. (May 11, 1945).

[39] H. Bundesmann, Melliand Textilberichte 16, 128 (1935).

[40] A. Klingelhöfer, H. Mendrzyk, and H. Sommer, Wiss. Abhandl. deut. Materialprüfungsanstalt. 1, 15; Chem. Zentr. 11, 2249-50 (1940).

[41] A. Klingelhöfer, H. Mendrzyk, and H. Sommer, Wiss. Abhandl. deut. Materialprüfungsanstalt. 1, 15; Chem. Zentr. 11, 2249-50 (1940).

[42] H. Wakeham and E. L. Skau, J. Am. Chem. Soc. 67, 268 (1945); H. Wakeham, W. Strickland, and E. L. Skau, Am. Dyestuff Reptr. 34, 178 (1945).

[43] S. Baxter and A. B. D. Cassie, J. Textile Inst. 36, 167 (1945).

[44] R. Wenzel, Ind. Eng. Chem. 28, 988 (1936).

[45] G. J. Mandikos and B. A. Ryberg, Am. Dyestuff Reptr. 34, 37 (1945).

[46] R. Wenzel, Am. Dyestuff Reptr. 25, 1598 (1936).

[47] N. K. Adam, The physics and chemistry of surfaces. (Oxford University Press, London, 1941).

[48] H. W. Stiegler and S. M. Hood, Am. Dyestuff Reptr. 28, 285 (1939).

[49] Textile research supplement No. 2 (Nov. 1942) and subsequent personal communication from staff of Milton Harris Associates.

[50] J. E. Simpson, Am. Dyestuff Reptr. 35, 243 (1946).

[51] NBS Commercial Standard CS59-44, par. 24 to 26a and 74 to $76 d$ (1944).

[52] Personal communication from the staff at the Philadelphia Quartermaster Depot.

[53] K. Lauer, Kolloid-Z. 107, Heft 2, 86 (1944).

ADDITIONAL REFERENCES NOT CITED IN TEXT

S. Mierzinski, The waterproofing of fabrics (D. Van Nostrand Co., New York, N. Y. 1903); also translation of $3 \mathrm{~d}$ ed. by A. Morris \& H. Robson (Scott, Greenwood \& Co., 1920).

H. Jaeger, European methods of waterproofing fabrics with formulae for ordinary and continuous processing, Melliand Textilber. 1, 123 (April 1929); 1, 253 (May 1929).

Waterproofing and showerproofing, Textile Colorist 54, 87, and 130 (1932).

A. J. Kelley, Textiles: Flame and waterproofing, cotton 98, No. 12, 53 (1934).

W. M. Scott, The testing of textiles for waterproofness, Am. Dyestuff Reptr. 2 \%, 479 (1938).

T. Stenzinger, Review and criticism of the methods of testing waterproof or water repelling impregnations, Am. Dyestuff Reptr. 27, 407 (1938)。 
R. Flint, The hydrophobing of artificial fibers and fabrics, Silk And Rayon 13, 808 (1939).

C. A. Norris, Water-resistant finishes, Textile Colorist 62, $165(1940)$.

F. J. Van Antwerpen, Chemical repellents, Ind. Eng. Chem. 33, 1514 (1941).

B. Monsaroff, waterproofing textile fabrics, Can. Chem. Process Inds. 26, 265 (1942).

Eric Croen, Water-repellent and waterproof finishes for Textiles, Cotton 10\%, No. 1, 63-66 (1943).

G. A. Slowinske, Evaluating water repellency of fabrics, Textile Mfr. 70, 268 (1944).

H. P. Holman and T. D. Jarrell, Effects of treating materials and outdoor exposure upon water-resistance and tensile strength of cotton duck, Textile World $\mathbf{7 3 ,} 3103$ (1928).

Effects of waterproofing materials and outdoor exposure upon the tensile strength of cotton yarn, Ind. Eng. Chem. 15, 236 (1923).

G. Barr, The determination of waterproofness of "porous" waterproof fabrics, Dept. Sci. \& Indl. Research, second Report of the Fabrics Co-ordinating Research Committee, His Majesty's Stationery Office, p. 113-139 (London 1929).

A. J. Hall, Waterproofing with colloidal aluminum hydroxide, Textile Colorist 54, 616 (1932).

S. Lenher and C. A. Slowinske, Mildewproofing and waterproofing of textile fibers, Am. Dyestuff Reptr. 25, 326 (1936).

N. K. Adam, Detergent action and its relation to wetting and emulsification, J. Soc. Dyers Colourists 53, 121 (1937).
Waterproofing cotton duck and canvas, Am. Dvestuff Reptr. 27, 507 (1938).

H. Zeyferth and O. M. Morgan, The canvas disc wetting test, Am. Dyestuff Reptr. 27, 525 (1938).

C. E. Mullen, Velan and similar water-repellent finishes, Textile Colorist 60, 96, 231 (1938).

G. A. Slowinske, A new type water repellent, Am. Dyestuff Reptr. 28, 647 (1939).

L. Stein, Hygenic and technical aspects of water-repellent clothing, Am. Dyestuff Reptr. 29, 352 (1940).

C. H. S. Tupholme, Water and Washing resistant finishes on textiles, Am. Dyestuff Reptr. 29, 466 (1940).

W. C. Hunter-Turner, Fats and waxes in disguise, Am. Dyestuff Reptr. 30, 371, 399 (1941).

G. A. Slowinske, The Evaluation of water-resisting textile finishes, Am. Dyestuff Reptr. 30, 6, (1941).

W. Lang, Aluminum acetate proofed khaki, J. Textile Inst. 32, A563 (1941).

C. E. Salkeld, Some modern war-time finishes, Textile Colorist 64, 245 (1942)

W. R. Lang, Waterproofing heavy woolens by aluminum acetate, Textile Colorist 64, 300 (1942).

A. J. Hall, Waterproofing of acetate rayon materials, Textile Colorist 64, 275 (1942).

Chemical stratagems in waterproofing process, "Cri. tanalyst" Textile Colorist 64, 95 (1942).

L. G. Lawries, The waterproofness of fabrics permeable to air J. Textile Inst. 33, 549 to 52 (1942).

Washington, September 13, 1946. 